\title{
Magnetic properties of nanostructured systems based on $\mathrm{TbFe}_{2}$
}

\author{
R. Ranchal*, V. Gutiérrez-Díez, V. González-Martín \\ Dpto. Física de Materiales, Fac. CC. Físicas, Universidad Complutense de Madrid. Ciudad Universitaria s/n, Madrid 28040, Spain
}

\begin{abstract}
A B S T R A C T
The aim of this work is to study the magnetic properties of annealed $\left[\mathrm{Fe}_{3} \mathrm{Ga} / \mathrm{TbFe}_{2}\right]_{n}$ heterostructures grown by sputtering at room temperature. The interest of investigating multilayers comprised of $\mathrm{TbFe}_{2}$ and $\mathrm{Fe}_{3} \mathrm{Ga}$ is their complementary properties in terms of coercivity and magnetostriction. We have studied the thickness combination which optimizes the magnetic and magnetostrictive properties of the annealed multilayers. The crystallization of the Laves phase upon the thermal treatment in heterostructures with thick $\mathrm{TbFe}_{2}$ layers promotes the increase of the coercivity. This crystallization seems to be prevented by the low mechanical stiffness of the $\mathrm{Fe}_{3} \mathrm{Ga}$. $\left[\mathrm{Fe}_{3} \mathrm{Ga} / \mathrm{TbFe}_{2} l_{n}\right.$ heterostructures show promising characteristics, $\lambda$ of $340 \mathrm{ppm}$ and $\mathrm{a} H_{\mathrm{C}}$ of $220 \mathrm{Oe}$, for the development of new magnetostrictive devices.
\end{abstract}

Keywords:

Sputtering

$\mathrm{TbFe}_{2}$

Galfenol

Thin films

Laves phase

Coercivity

Magnetostriction

\section{Introduction}

Magnetostrictive materials are widely employed in sensors and actuators devices due to their capability to be used in wireless technology. Materials systems with a high magnetostriction constant $(\lambda)$ and a low coercive field $\left(H_{C}\right)$ are required for the development of reliable devices. The crystalline $\mathrm{TbFe}_{2}$ Laves phase exhibits the highest magnetostriction constant at room temperature [1]. However, its high coercivity of $\sim 4 \mathrm{kOe}$, is a drawback for industrial applications [2]. Heterostructures comprised of $\mathrm{TbFe}_{2}$ and soft magnetic layers such as $\mathrm{Ni}, \mathrm{Fe}$, or $\mathrm{FeB}$ have already been studied [3-6]. In these systems, the combination of $\mathrm{TbFe}_{2}$ and low coercivity materials was expected to provide multilayers with a low $\mathrm{H}_{C}$ and a noticeably magnetostriction constant. Although the coercivity is low, the magnetostriction in some cases is also highly reduced. $\mathrm{TbFe}_{2} / \mathrm{FeCo}$ multilayers show excellent properties with a saturation magnetoelastic coupling coefficient ( $\lambda Y$, being $Y$ the Young's Modulus) of 27.5 MPa and a hysteresis of less than 25 Oe [7].

Galfenol $\left(\mathrm{Fe}_{1-x} \mathrm{Ga}_{x}\right)$ exhibits a pretty high $\lambda, 400 \mathrm{ppm}$ for quenched bulk samples with a $19 \%$ and $28 \%$ of Ga [8]. Furthermore, its low coercivity and high ductility make of Galfenol a very attractive material for magnetic sensors and actuators. Several studies have been devoted to the study of the structural and magnetostrictive properties of bulk [9-17] and more recently to the investigation of thin Fe-Ga films [18-23]. A review about the magnetostrictive properties of the Fe-Ga alloys has recently appeared [24]. Heterostructures comprised of $\mathrm{FeGa}$ and transition magnetic metals alloys such as $\mathrm{NiFe}$ and $\mathrm{FeCOB}$ have also been reported $[25,26]$. In this work we present the coercivity and magnetostrictive characteristics of annealed $\left[\mathrm{Fe}_{3} \mathrm{Ga} / \mathrm{TbFe}_{2}\right]_{n}$ heterostructures. The interest of these heterostructures is the possibility of achieving new materials with a pretty high magnetostriction but low coercivity due to the complementary properties of $\mathrm{TbFe}_{2}$ and $\mathrm{Fe}_{3} \mathrm{Ga}$ in terms of coercivity and magnetostriction. The experimental results presented in this work show the possibility of engineering these two characteristics by means of the layer thickness.

\section{Experimental techniques}

Samples were grown by the sputtering technique at room temperature on glass substrates. The Ar pressure during growth was $2 \times 10^{-3} \mathrm{mbar}$ and the power was $120 \mathrm{~W}$ for the deposition of the $\mathrm{TbFe}_{2}$ and $100 \mathrm{~W}$ for the $\mathrm{Fe}_{3} \mathrm{Ga}$ layers, respectively. Mo buffer and capping layers $(20 \mathrm{~nm})$ were used to protect the heterostructures against oxidation. They were deposited with a dc power of $90 \mathrm{~W}$ and at an Ar pressure of $2 \times 10^{-3}$ mbar. We have grown three different set of samples: (a) a set in which the $\mathrm{TbFe}_{2}$ thickness was kept constant at $12.5 \mathrm{~nm}$ whereas the $\mathrm{Fe}_{3} \mathrm{Ga}$ layer ranged between 12.5 and $100 \mathrm{~nm}$, (b) multilayers where the $\mathrm{Fe}_{3} \mathrm{Ga}$ thickness was fixed at $12.5 \mathrm{~nm}$ and the $\mathrm{TbFe}_{2}$ thickness ranged between 12.5 and $100 \mathrm{~nm}$, and (c) heterostructures where the thickness of the $\mathrm{TbFe}_{2}$ and $\mathrm{Fe}_{3} \mathrm{Ga}$ is the same and ranged between 12.5 and $100 \mathrm{~nm}$. Hereafter, we will denote these set of samples as (a), (b) and (c). The three series of samples have one in common, the heterostructure with the thinnest studied layers $(12.5 \mathrm{~nm})$, i.e. $\left[\mathrm{Fe}_{3} \mathrm{Ga}(12.5 \mathrm{~nm}) / \mathrm{TbFe}_{2}(12.5 \mathrm{~nm}) \mathrm{l}_{16}\right.$. Hysteresis loops at room temperature were carried out in a vibrating sample magnetometer (VSM). The optical cantilever method has been used to infer the magnetostrictive properties of the heterostructures [27]. Thermal treatments were 
carried out in Ar atmosphere during $1 \mathrm{~h}$ at $400^{\circ} \mathrm{C}$. After the annealing, samples were cooled-down at a rate of $20^{\circ} \mathrm{C} / \mathrm{min}$ because fast cooling-downs enhance the magnetost rictive properties of the Galfenol layers [8].

\section{Experimental results and discussion}

In a previous work, we reported on the structural properties of $\left[\mathrm{TbFe}_{2} / \mathrm{Fe}_{3} \mathrm{Ga}\right]_{n}$ multilayers. We observed signatures of the bcc structure in the $\mathrm{Fe}_{3} \mathrm{Ga}$ layers and of the cubic Laves phase in the $\mathrm{TbFe}_{2}$ layers [28]. In this work, we study the thickness combination which optimizes the magnetic and magnetostrictive properties of $\left[\mathrm{Fe}_{3} \mathrm{Ga} / \mathrm{TbFe}_{2}\right]_{n}$ multilayers. We have only investigated annealed samples because we have previously observed the low magnetostrictive properties of as-grown $\mathrm{TbFe}_{2}$ thin films grown by sputtering at room temperature [29]. The thermal treatments are necessary to enhance the magnetoelastic properties because the $\mathrm{TbFe}_{2}$ phase with the highest magnetostriction constant is the crystalline Laves phase. Following a previous work of Clark [2], the $H_{\mathrm{C}}$ of $\mathrm{TbFe}_{2}$ is related to its structural crystallinity and hence, in this work we use the coercivity of the heterostructures to track the crystallization of the $\mathrm{TbFe}_{2}$ layers upon the thermal treatment.

We have inferred the coercivity of the annealed $\left[\mathrm{Fe}_{3} \mathrm{Ga} / \mathrm{TbFe}_{2}\right]_{n}$ heterostructures from the hysteresis loops recorded at room temperature (Fig. 1(a)). In Fig. 1(b) we show the dependence of the $\mathrm{H}_{\mathrm{C}}$ on the layer thickness for the three series of samples. The coercivity of the heterostructure of set (a) with $100 \mathrm{~nm} \mathrm{Fe}_{3} \mathrm{Ga}$
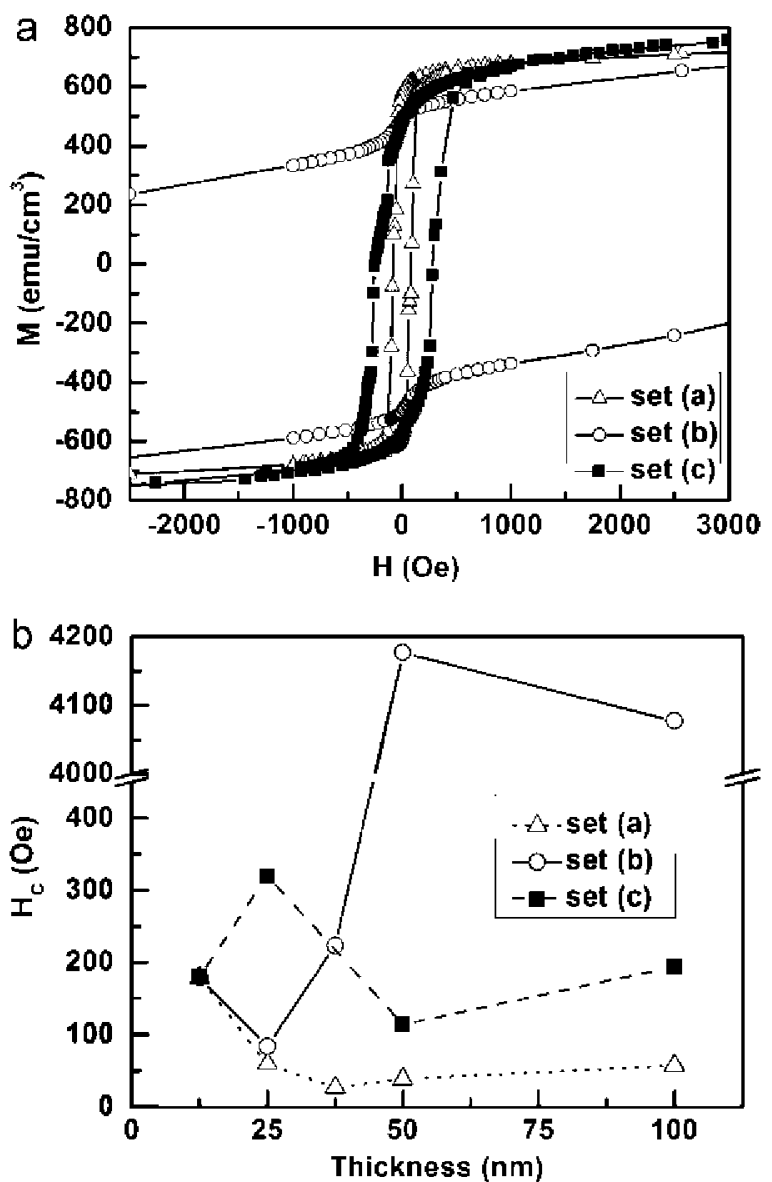

Fig. 1. (a) Hysteresis loops recorded at room temperature of three different heterostructures: set (a) $\left[\mathrm{Fe}_{3} \mathrm{Ga}(100 \mathrm{~nm}) / \mathrm{TbFe}_{2}(12.5 \mathrm{~nm})\right]_{3}(\Delta)$, set (b) $\left[\mathrm{Fe}_{3} \mathrm{Ga}(12.5 \mathrm{~nm}) / \mathrm{TbFe}_{2}(100 \mathrm{~nm})\right]_{3}(\mathrm{O})$, and set $(\mathrm{c})\left[\mathrm{Fe}_{3} \mathrm{Ga}(100 \mathrm{~nm}) / \mathrm{TbFe}_{2}(100 \mathrm{~nm})\right]_{2}$ (ש). (b) Coercivity as a function of the layer thickness of the three set of samples: set (a) $(\Delta)$, set (b) $(\bigcirc)$, and set $\mathrm{c}(\boldsymbol{\square})$. All the samples were annealed at $400^{\circ} \mathrm{C}$. layers, $H_{\mathrm{C}}=57 \mathrm{Oe}$, is similar to the value obtained in single $\mathrm{Fe}_{3} \mathrm{Ga}$ films, $65 \mathrm{Oe}$, deposited under the same growth conditions and also post-annealed at $400^{\circ} \mathrm{C}$. Moreover, in this set (a) of samples it is achieved the minimum coercivity among all the studied heterostructures, $H_{\mathrm{C}}=27 \mathrm{Oe}$, when the $\mathrm{Fe}_{3} \mathrm{Ga}$ thickness is $37.5 \mathrm{~nm}$. This $\mathrm{H}_{\mathrm{C}}$ is even lower than that of $\mathrm{Fe}_{3} \mathrm{Ga}$ single layers. This low $\mathrm{H}_{\mathrm{C}}$ value can be due to the antiferromagnetic coupling between the heavy rare earths (RE) and the magnetic transition metals (TM) [30]. In the $\mathrm{TbFe}_{2}$ layers there exists this antiferromagnetic coupling between the $\mathrm{Tb}$ and $\mathrm{Fe}$ atoms and it is also expected to exist in the $\mathrm{Fe}_{3} \mathrm{Ga} / \mathrm{TbFe}_{2}$ interfaces between the $\mathrm{Tb}$ and the Fe atoms of adjacent layers. This antiferromagnetic coupling decreases the coercivity as already observed in other systems consisted of RE and TM such as permalloy( $\left.\mathrm{Ni}_{80} \mathrm{Fe}_{20}\right)$ /gadolinium multilayers [31]. The presence of TbFeGa alloys at the interfaces can also account for this low $H_{C}$. This possibility will be discussed below.

In the set (b), there is a dramatic increase of the $H_{\mathrm{C}}$ up to 4 kOe when the $\mathrm{TbFe}_{2}$ thickness is higher than $37.5 \mathrm{~nm}$ (Fig. 1(b)). This strong increase of the $\mathrm{H}_{C}$ indicates a complete crystallization of the $\mathrm{TbFe}_{2}$ Laves phase. Samples of set (c) do not exhibit this strong increase of the coercivity pointing to a partially crystallization of the $\mathrm{TbFe}_{2}$ layers in those samples. $\mathrm{H}_{\mathrm{C}}$ is low in these heterostructures of set (c) even when the $\mathrm{TbFe}_{2}$ thickness is $100 \mathrm{~nm}$ being remarkable the $H_{C}$ of just 195 Oe obtained in the $\left[\mathrm{Fe}_{3} \mathrm{Ga}(100 \mathrm{~nm}) / \mathrm{TbFe}_{2}(100 \mathrm{~nm})\right]_{2}$ multilayer (Fig. 1). Then, the crystallization of the Laves phase takes place in heterostructures with $50 \mathrm{~nm} \mathrm{TbFe}_{2}$ layers deposited on $12.5 \mathrm{~nm} \mathrm{Fe} \mathrm{Ga}_{3} \mathrm{Gayers}$ [set (b)] but it is prevented when the $\mathrm{TbFe}_{2}$ is deposited on top of $\mathrm{Fe}_{3} \mathrm{Ga}$ layers with the same thickness [set (c)].

It is also important to remark the shape of the hysteresis loops of the samples of set (b) and (c) presented in Fig. 1(b). This shape indicates the presence of two uncoupled magnetic phases with different coercivity. This behavior is similar to what is observed in exchange-spring magnets comprised of soft and hard magnetic phases in which the layer thickness has not been optimized and each magnetic system rotates at a different magnetic field [32]. Although we do not observe this behavior in all the samples, it is important to notice that the layer thickness should be optimized not only to provide a low $H_{C}$ and a high $\lambda$ but also to achieve structures in which the magnetic systems are rigidly coupled.

Previous studies on sputtered Tb-Fe thin films have reported about the influence of the mechanical stiffness of the substrate and/or the buffer layer on the crystallization process of this material system [29,33]. Materials with a high $Y / \alpha$ factor, being $\alpha$ the thermal expansion coefficient, promote the crystallization of the Laves phase. It is important to remark that the best results are related to a high $Y / \alpha$ factor in the substrate or buffer and not to a $Y / \alpha$ close to that of $\mathrm{TbFe}_{2}$. Thus, although $\mathrm{TbFe}_{2}$ and $\mathrm{Fe}_{3} \mathrm{Ga}$ have similar $Y / \alpha$ values of around $Y / \alpha=6 \times 10^{6} \mathrm{GPaK}$, this value is low in comparison to $\mathrm{Mo}\left(71 \times 10^{6} \mathrm{GPa} \mathrm{K}\right)$ or $\mathrm{Si}\left(43 \times 10^{6} \mathrm{GPa} \mathrm{K}\right)$ that are known to promote an optimum crystallization of the Laves phase [29]. Therefore, in set (c) the coercivity can be low because the $\mathrm{TbFe}_{2}$ are deposited on top of $\mathrm{Fe}_{3} \mathrm{Ga}$ layers that have a low $\mathrm{Y} / \alpha$ factor.

Another possibility for the low $H_{C}$ achieved in some heterostructures is the presence of TbFeGa alloys at the interfaces. We observed these ternary alloys in the interfaces of as-grown $\left[\mathrm{TbFe}_{2} / \mathrm{Fe}_{3} \mathrm{Ga}\right]_{n}$ multilayers [28]. The thermal treatments promote the diffusion of the $\mathrm{Tb}$ atoms from the interfaces to the $\mathrm{Tb}-\mathrm{Fe}$ layers although this diffusion process seemed to be prevented in samples comprised of layers thinner than $50 \mathrm{~nm}$. In those $\left[\mathrm{TbFe}_{2} / \mathrm{Fe}_{3} \mathrm{Ga}\right]_{n}$ multilayers with thin layers, the $\mathrm{Tb}-\mathrm{Fe}$ layers have a lower $\mathrm{Tb}$ content than the $33 \%$ related to the $\mathrm{TbFe}_{2}$ composition. Although TbFeGa alloys can be present in heterostructures with thin layers studied in this work, the low $H_{\mathrm{C}}$ achieved in the set (c) cannot be explained considering the presence of these alloys. We have obtained low $H_{C}$ values in the samples of set (c) even when the $\mathrm{TbFe}_{2}$ and $\mathrm{Fe}_{3} \mathrm{Ga}$ 
layers have a thickness of $100 \mathrm{~nm}$ (Fig. 1). The presence of TbFeGa alloys cannot fully explain the experimental results presented in this work. Therefore, the crystallization process promoted by the mechanical stiffness of the buffer layer on top the $\mathrm{TbFe}_{2}$ is deposited seems to play an important role on the magnetic properties of $\left[\mathrm{Fe}_{3} \mathrm{Ga} / \mathrm{TbFe}_{2}\right]_{n}$ multilayers.

A representative magnetostriction measurement is shown in Fig. 2(a) being summarized the dependence of the magnetostriction constant on the thickness layer for the three set of samples in Fig. 2(b). Large $\lambda$ values, $>1 \times 10^{3} \mathrm{ppm}$, are achieved in samples of set (b) with $\mathrm{TbFe}_{2}$ thicknesses above $37.5 \mathrm{~nm}$. In these samples the Laves phase is crystallized being possible to obtain large magnetostriction constants. Nevertheless, the high coercivity of these heterostructures (Fig. 1(b)) prevents their use in reliable applications.

In this work, we are investigating not only the route to achieve high magnetostrictive but also low coercivity systems. And thus, in Fig. 3 we present the magnetostriction constant as a function of the coercivity. We have just considered those samples with a $H_{C}$ lower than 300 Oe. It is noteworthy that bulk quenched Galfenol samples show a $\lambda$ of $400 \mathrm{ppm}$ but in sputtered $\mathrm{Fe}_{81.6} \mathrm{Ga}_{18.4}$ thin films have been reported maximum values of $150 \mathrm{ppm}$ [20]. Our annealed samples have $\lambda$ values below $100 \mathrm{ppm}$ when the coercivity is lower than 150 Oe. Nevertheless, $\lambda$ increases up to $340 \mathrm{ppm}$ when the coercivity is 2200 e. These optimum values have been achieved in the $\left[\mathrm{Fe}_{3} \mathrm{Ga}(12.5 \mathrm{~nm}) / \mathrm{TbFe}_{2}(37.5) \mathrm{nm}\right]_{7}$ heterostructure of set (b). Samples of that set (b) with thicker $\mathrm{TbFe}_{2}$ layers exhibit a huge coercivity while with thinner layers the $\lambda$ is too small. Then, with this
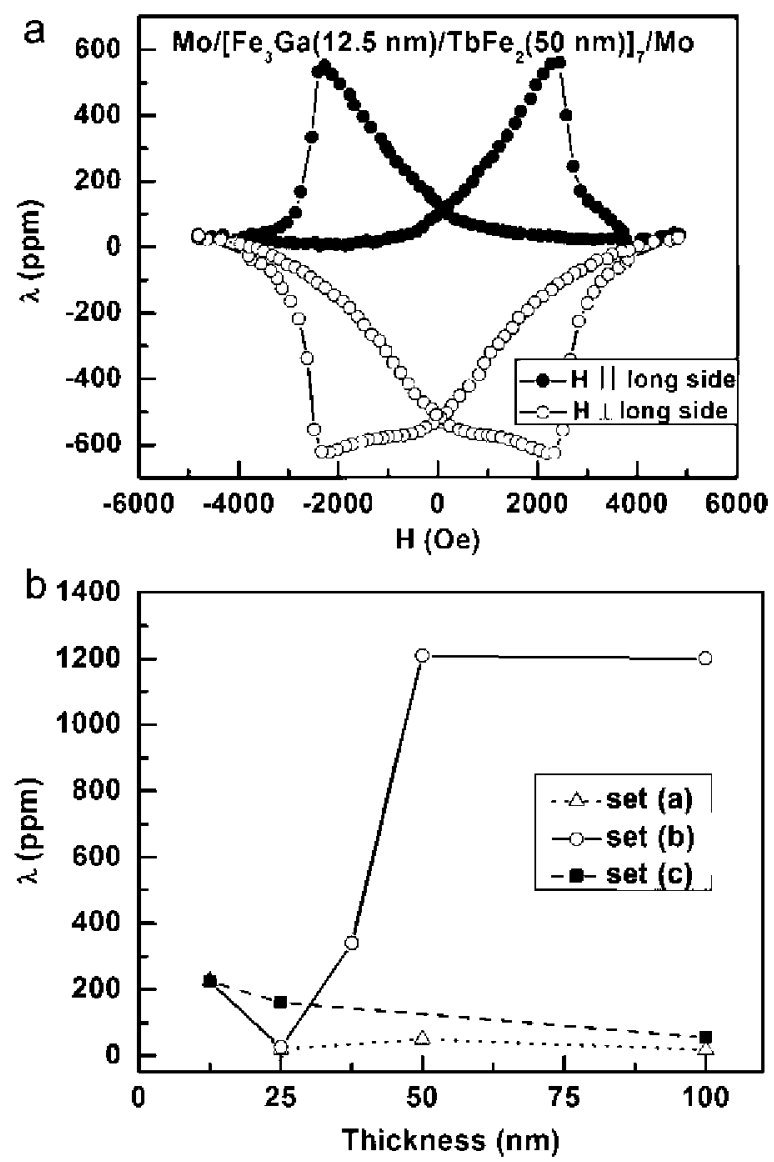

Fig. 2. (a) Magnetostriction as a function of the applied magnetic field of the $\left[\mathrm{Fe}_{3} \mathrm{Ga}(12.5 \mathrm{~nm}) / \mathrm{TbFe}_{2}(50 \mathrm{~nm})\right]_{7}$. The direction of the magnetic field is parallel $(\bullet)$ and perpendicular $(\bigcirc)$ to the long side of the cantilever. (b) Magnetostriction constant as a function of the thickness layer for the three set of samples: set (a) $(\triangle)$, set (b) (O), and set c (

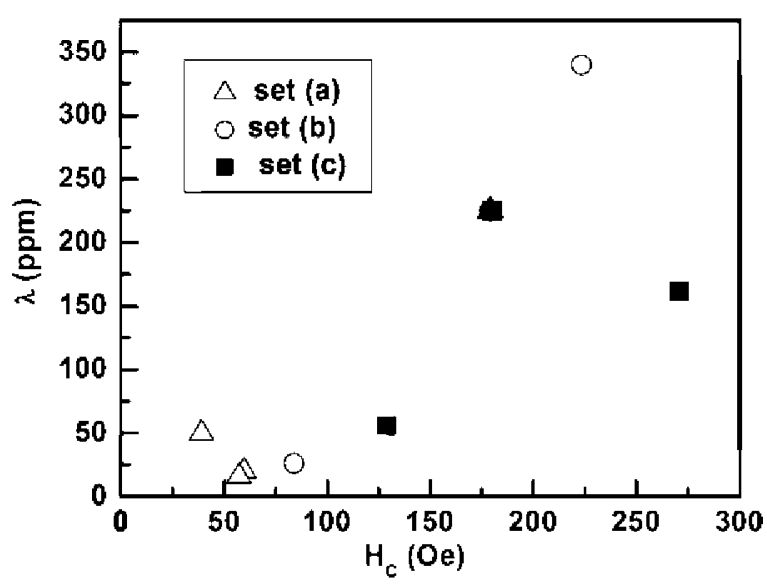

Fig. 3. Magnetostriction constant as a function of the coercivity for the three set of samples: set (a) $(\triangle)$, set (b) $(\bigcirc)$, and set $c(\mathbb{\square})$. We have not included in the graph those samples with a coercivity higher than $2750 \mathrm{Oe}$.

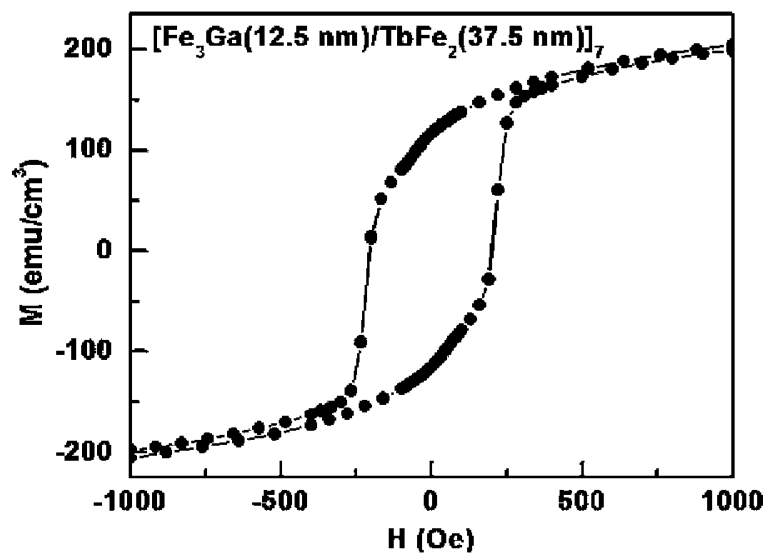

Fig. 4. Hysteresis loop at room temperature of the $\left[\mathrm{Fe}_{3} \mathrm{Ga}(12.5 \mathrm{~nm})\right]$ $\left.\mathrm{TbFe}_{2}(37.5 \mathrm{~nm})\right]_{7}$ heterostructure.

combination of thicknesses, $\left[\mathrm{Fe}_{3} \mathrm{Ga}(12.5 \mathrm{~nm}) / \mathrm{TbFe}_{2}(37.5) \mathrm{nm}\right]_{7}$, the $\mathrm{TbFe}_{2}$ is partially crystallized as indicated by its moderate $\mathrm{H}_{\mathrm{C}}$ being possible to enhance the magnetostrictive properties without a strong increase of the $\mathrm{H}_{\mathrm{C}}$. In the rest of the samples, the crystallization of the $\mathrm{TbFe}_{2}$ is so negligible that the magnetostriction constant is rather low. Furthermore, the hysteresis loop of the optimized sample, $\left[\mathrm{Fe}_{3} \mathrm{Ga}(12.5 \mathrm{~nm}) / \mathrm{TbFe}_{2}\right.$ (37.5) $\mathrm{nm}_{7}$, shows that the hard and soft magnetic layers are strongly coupled since there is just one magnetization jump in the loop [Fig. 4]. Although not so good as those values reported by Quandt and Ludwig in $\mathrm{TbFe}_{2} / \mathrm{FeCo}$ multilayers [7], $\lambda \sim 400 \mathrm{ppm}$ and $H_{\mathrm{C}} \sim 25$ Oe, our results show the promising characteristics of the $\left[\mathrm{Fe}_{3} \mathrm{Ga} / \mathrm{TbFe}_{2}\right]_{n}$ heterostructures. Therefore, the optimization of the layer thickness appears as a route to engineer the magnetic and magnetostrictive properties of the $\left[\mathrm{Fe}_{3} \mathrm{Ga} / \mathrm{TbFe}_{2}\right]_{n}$ multilayers.

\section{Conclusions}

In conclusion, our experimental results indicate that the combination of hard and soft magnetostrictive materials such as $\mathrm{TbFe}_{2}$ and $\mathrm{Fe}_{3} \mathrm{Ga}$ is a promising route to produce new magnetostrictive systems with a low coercivity and a high magnetostriction constant. Multilayers comprised of thick $\mathrm{TbFe}_{2}$ layers show a magnetostriction constant higher than $1 \times 10^{3} \mathrm{ppm}$. Nevertheless, their high $H_{\mathrm{C}}$ of around $4 \mathrm{kOe}$ prevents their use in applications. The layer thickness is an important factor to engineer the magnetic properties of these heterostructures due to the influence of the buffer 
mechanical stiffness $(\mathrm{Y} / \alpha)$ on the $\mathrm{TbFe}_{2}$ crystallization process. $\left[\mathrm{Fe}_{3} \mathrm{Ga} / \mathrm{TbFe}_{2}\right]_{n}$ heterostructures show promising characteristics with a $\lambda$ of $340 \mathrm{ppm}$ and $\mathrm{a} H_{\mathrm{C}}$ of 2200 .

\section{Acknowledgments}

This work has been financially supported by the Regional Government of Madrid and the Universidad Complutense de Madrid trough the project CCG10-UCM/MAT-4621.

\section{References}

[1] A.E. Clark, H.S. Belson, Phys. Rev. B 5 (1972) 3642.

[2] A.E. Clark, Appl. Phys. Lett. 23 (1973) 642.

[3] H.-S. Lee, C. Cho, IEEE Trans. Magn. 44 (2008) 4049.

[4] E. Quandt, A. Ludwig, J. Mencik, E. Nold, J. Alloys Compd. 258 (1997) 6232

[5] T. Shima, K. Takanashi, H. Fujimori, J. Magn. Magn. Mater. 239 (2002) 573.

[6] C. Prados, I. Panagiotopoulus, G.C. Hadjipanayis, J.J. Freijo, A. Hernando, IEEE Trans. Magn. 33(1997) 3712.

[7] E. Quandt, A. Ludwig, Sens. Actuators A 81 (2000) 275

[8] A.E. Clark, M. Wun-Fogle, J.B. Restorf, T.A. Lograsso, J.R. Cullen, IEEE Trans. Magn. 37 (2001) 2678

[9] A.E. Clark, J.B. Restorff, M. Wun-Fogle, T. Lograsso, D. Schalgel, IEEE Trans. Magn. $36(2000) 3238$

[10] A.E. Clark, M. Wun-Fogle, J.B. Restorf, K.W. Dennis, T.A. Lograsso, R.W. McCallum, J. Appl, Phys. 97 (2005) 10M316.

[11] O. Ikeda, R. Kainuma, I. Ohnuma, K. Fukamachi, K. Ishida, J. Alloys Compd. 347 (2002) 198 .
[12] H. Cao, F. Bai, J. Li, D.D Viehland, T A Lograsso, P.M Gehring I Alloys Compd. 465 (2008) 244

[13] Q. Xing, T.A. Lograsso, Appl. Phys. Lett. 93 (2008) 182501.

[14] Q. Xing, Y. Du, R.J. McQueeney, T.A. Lograsso, Acta Mater. 56 (2008) 4536.

[15] H. Cao, P.M. Gehring, C.P. Devreugd, J.A. Rodríguez-Rivera, J. Li, D. Viehland, Phys. Rev. Lett. 102 (2009) 127201

[16] M. Laver, C. Mudivarthi, J.R. Cullen, A.B. Flatau, W.C. Chen, S.M. Watson, M. Wuttig, Phys. Rev. Lett. 105 (2010) 027202.

[17] M.P. Ruffoni, S. Pascarelli, R. Grössinger, R. Sato Turtelli, C. Bormio-Nunes, R.F. Pettifer, Phys. Rev. Lett. 101 (2008) 147202

[18] A. Javed, N.A. Morley, M.R.J. Gibbs, J. Magn. Magn. Mater. 321 (2009) 2877.

[19] N.A. Morley, A. Javed, M.R.J. Gibbs, J. Appl. Phys. 105 (2009) 07 A912.

[20] R.R. Basantkumar, B.]. Hills Stadler, W.P. Robinson, E.M. Summers, IEEE Trans Magn. 42 (2006) 3102.

[21] J.L. Weston, A. Butera, T.A. Lograsso, M.Shamsuzzoha, I.\#\#I. Zana, G. Zangari, J. Barnard, IEEE Trans. Magn. 38 (2002) 2832.

[22] A. Butera, J. Gómez, J.L. Weston, J.A. Barnard, J. Appl. Phys. 98 (2005) 033901.

[23] R.A. Dunlap, N.C. Deschamps, R.E. Mar, S.P. Farrell, J. Phys.: Condens. Matter 18 (2006) 4907

[24] J. Atulasimha, A.B. Flatau, Smart Mater. Struct. 20 (2011) 043001.

[25] N. Lupu, H. Chiriac, P. Pascariu, J. Appl. Phys. 103 (2008) 07 B511.

[26] N. Lupu, P. Pascariu, C. Gherasim, H. Chiriac, IEEE Trans. Magn. 44 (2008) 3005.

[27] D. Ciudad, J.L. Prieto, I. Lucas, C. Aroca, P. Sánchez, J. Appl. Phys. 101 (2007) 043907.

[28] R. Ranchal, V. González-Martín, J. Appl. Phys. 110 (2011) 053901.

[29] R. Ranchal, J.L. Prieto, P. Sánchez, C. Aroca, J. Appl. Phys. 107 (2010) 113918

[30] R.E. Camley, Phys. Rev. B 39 (1989) 12316.

[31] R. Ranchal, C. Aroca, E. López, New J. Phys. 10 (2008) 013013.

[32] E.E. Fullerton, J.S. Jiang, S.D. Bader, J. Magn. Magn. Mater. 200 (1999) 392.

[33] R. Ranchal, E. López, J.L. Prieto, C. Aroca, Acta Mater. 59 (2011) 2865. 